\title{
MANFAAT HELM DALAM MENCEGAH KEMATIAN AKIBAT CEDERA KEPALA PADA KECELAKAAN LALU LINTAS
}

\author{
${ }^{1}$ Stefie W. Antou \\ ${ }^{2}$ James F. Siwu \\ ${ }^{2}$ Johannis F. Mallo \\ ${ }^{1}$ Kandidat Skripsi Fakultas Kedokteran Universitas Sam Ratulangi Manado \\ ${ }^{2}$ Bagian Ilmu Kedokteran Forensik dan Medikolegal Fakultas Kedokteran \\ Universitas Sam Ratulangi Manado \\ Email: stefiewinz@yahoo.com
}

\begin{abstract}
Nowadays, the occurence of traffic accidents is not uncommon, especially among two-wheeled-vehicle riders. There are four causes of traffic accidents: human being, vehicle, road, and environment. From the human factor, the main cause is the riders' disregard for traffic rules and traffic signs. The most common cause of deaths is head injuries due to not wearing a helmet or wearing a non-standardized helmet. In addition to the mis-use of helmets, related head injuries should be accurately identified from the aspects of causes and types of injuries. This will also affect management and prevention. It is suggested the benefit of helmets and the impacts of head injuries be made known.
\end{abstract}

Keywords: helmet, head injuries, traffic accidents.

\begin{abstract}
Abstrak: Dewasa ini kecelakaan lalu lintas (KLL) merupakan peristiwa yang sudah tidak jarang terjadi, terutama pada pengendara kendaraan bermotor roda dua. Penyebab KLL disebabkan oleh empat faktor utama yaitu: faktor manusia, kendaraan, jalan, dan lingkungan. Faktor manusia yang tersering ialah para pengendara yang tidak mematuhi peraturan dan rambu-rambu lalu lintas. Penyebab terbanyak kematian akibat KLL ialah cedera kepala yang diakibatkan pengendara tidak memakai helm atau memakai helm yang tidak sesuai dengan standar nasional Indonesia. Selain penggunaan helm, pengetahuan terhadap bahaya cedera kepala harus dipahami lebih jelas dari sisi penyebab, jenis cedera kepala, penatalaksanaan, dan pecegahannya. Disarankan untuk mengadakan penyuluhan mengenai manfaat helm dan bahaya cedera kepala.
\end{abstract}

Kata kunci: helm, cedera kepala, kecelakaan lalu lintas.

Data Departemen Kesehatan Republik Indonesia tahun 2006 menunjukkan bahwa kecelakaan lalu lintas (KLL) merupakan penyebab utama dari kematian dengan berbagai sebab dan menempati urutan ke10 sebagai penyebab dari semua kematian. Dewasa ini, kejadian KLL makin meningkat dalam jumlah maupun jenisnya dengan prakiraan angka kematian dari 5,1 juta pada tahun 1990 menjadi 8,4 juta pada tahun 2020 atau meningkat sebanyak 65\%. KLL merupakan salah satu masalah kesehatan masyarakat yang memengaruhi semua sektor kehidupan. Pada tahun 2002 diperkirakan sebanyak 1,18 juta meninggal karena kecelakaan. Cedera kepala akibat KLL sudah menjadi masalah utama kesehatan masyarakat dan lebih dari dua pertiga ditemukan di negara berkembang. ${ }^{1}$

Menurut WHO, tahun 2004 Case Fatality Rate (CFR) oleh cedera akibat KLL tertinggi dijumpai di beberapa Negara Amerika Latin (41,7\%), Korea Selatan (21,9\%), dan Thailand (21,0\%). Menurut 
Gillian yang dikutip oleh Ibrahim (1997) di Amerika Serikat terdapat 500.000 kasus cedera kepala setiap tahunnya; dan sekitar $18-30 \%$ meninggal dalam empat jam pertama sebelum sampai ke rumah sakit. ${ }^{2}$ Temuan Polri oleh Jenderal Pol. Drs.Timur Pradopo pada Rapat Kerja Teknis Lalu Lintas 27 Februari 2012 ialah setiap hari 89 orang meninggal dunia di jalan akibat KLL. Pada tahun 2010 Polri mencatat 31.234 orang meninggal dunia, kemudian meningkat menjadi 32.185 pada tahun 2011 dengan variasi penyebab yang semakin kompleks. ${ }^{3}$ Data direktorat lalu lintas Polri menyebutkan tingkat volume lalu lintas di Indonesia dalam beberapa tahun terakhir ini berkembang cukup pesat khususnya sepeda motor, yang merupakan penyumbang terbesar terjadinya KLL. ${ }^{4}$

\section{PENGGUNAAN HELM}

Menurut data sejarah, helm pertama kali diciptakan sebagai bagian dari baju pelindung peradaban Yunani kuno yaitu Romawi klasik hingga akhir abad ke 17. Pada masa tersebut helm terbuat dari besi oleh karena fungsi helm sebagai bagian dari baju pelindung. Fungsi helm ini sebatas untuk keperluan perang yang dapat melindungi kepala dari sabetan pedang musuh dan datangnya anak panah atau peluru berkecepatan rendah. ${ }^{4}$

\section{Kualifkasi helm SNI (Standar Nasional Indonesia)}

Dari segi material, bahan helm harus memenuhi ketentuan sebagai berikut, yaitu: dibuat dari bahan yang kuat dan bukan logam; bahan pelengkap helm harus tahan lapuk, tahan air dan tidak dapat terpengaruh oleh perubahan suhu; bahan-bahan yang bersentuhan dengan tubuh tidak boleh terbuat dari bahan yang dapat menyebabkan iritasi atau penyakit pada kulit; dan tidak mengurangi kekuatan terhadap benturan maupun perubahan fisik sebagai akibat dari bersentuhan langsung dengan keringat, minyak dan lemak si pengguna. ${ }^{4}$

Dari segi konstruksinya, helm harus memenuhi persyaratan sebagai berikut, yaitu: helm harus terdiri dari tempurung keras dengan permukaan halus; lapisan peredam benturan dan tali pengikat ke dagu; dan tinggi helm sekurang-kurangnya $114 \mathrm{~mm}$ diukur dari puncak helm ke bidang utama yaitu bidang horizontal yang melalui lubang telinga dan bagian bawah dari dudukan bola mata. Untuk keliling lingkaran bagian dalam helm terdapat ukuran $\mathrm{S}$, M, L, dan XL (Tabel 1). ${ }^{1}$

Tabel 1. Keliling lingkaran bagian dalam helm. ${ }^{4}$

\begin{tabular}{cc}
\hline Ukuran & $\begin{array}{c}\text { Keliling lingkaran bagian } \\
\text { dalam helm } \\
(\mathbf{m m})\end{array}$ \\
\hline $\mathrm{S}$ & $500-<540$ \\
$\mathrm{M}$ & $540-<580$ \\
$\mathrm{~L}$ & $580-<620$ \\
$\mathrm{XL}$ & $\geq 620$ \\
\hline
\end{tabular}

Tempurung harus terbuat dari bahan yang keras, sama tebal dan homogen, tidak menyatu dengan pelindung muka dan mata, serta tidak boleh mempunyai penguatan setempat. Tempurung tidak boleh mempunyai tonjolan keluar yang tingginya melebihi $5 \mathrm{~mm}$ dari permukaan luar tempurung, dan setiap tonjolan harus ditutupi dengan bahan lunak dan tanpa bagian tepi yang tajam. ${ }^{5}$

Peredam benturan terdiri dari lapisan peredam kejut yang dipasang pada permukaan bagian dalam tempurung dengan tebal sekurang-kurangnya $10 \mathrm{~mm}$. Tali pengikat dagu lebarnya sekurang-kurangnya $20 \mathrm{~mm}$ dan harus benar-benar berfungsi sebagai pengikat helm ketika dikenakan di kepala serta dilengkapi dengan penutup telinga dan tengkuk. Lebar sudut pandang sekeliling sekurang-kurangnya $105^{\circ}$ pada tiap sisi dan sudut pandang vertikal sekurangkurangnya $30^{\circ}$ di atas dan $45^{\circ}$ di bawah bidang utama. ${ }^{5}$

Helm harus dilengkapi dengan pelindung telinga, penutup leher, pet yang bisa dipindahkan, tameng atau tutup dagu, memiliki daerah pelindung helm, dan helm tidak boleh memengaruhi fungsi aura dari 
pengguna terhadap suatu bahaya. Lubang ventilasi dipasang pada tempurung sedemikian rupa sehingga dapat mempertahankan suhu pada ruang antara kepala dan tempurung. Setiap penonjolan ujung dari paku/kelim harus berupa lengkungan dan tidak boleh menonjol $>2 \mathrm{~mm}$ dari permukaan luar tempurung. Helm harus dapat dipertahankan di atas kepala pengguna dengan kuat melalui atau menggunakan tali dengan cara mengaitkan di bawah dagu atau melewati tali pemegang di bawah dagu yang dihubungkan dengan tempurung. ${ }^{5}$

\section{Definisi dan jenis-jenis helm}

\section{Helm}

Helm adalah topi pelindung kepala yang dibuat dari bahan tahan benturan, yang dipakai oleh tentara, anggota barisan pemadam kebakaran, pekerja tambang, penyelam, atau pengendara sepeda motor. ${ }^{4}$

Terdapat beberapa jenis helm pengendara sepeda motor (Gambar 1) dengan kelebihan dan kekurangan masing-masing. ${ }^{4}$

1. Helm cetok: kelebihan helm jenis ini ialah mampu melindungi bagian atas kepala meski dengan tingkat perlindungan yang sangat minim, sedangkan kekurangannya ialah tidak adanya bagian yang menutupi telinga sehingga helm ini bisa membahayakan pendengaran penguna akibat suara bising yang ditimbulkan ketika berkendara.

2. Helm half-facelopen-face: kelebihan helm jenis ini ialah melindungi bagian atas, samping (telinga), dan belakang kepala (leher). Helm jenis ini memberikan perlindungan yang sedikit lebih baik dibanding helm cetok, serta mudah dipakai dan dilepas. Kekurangannya ialah suara bising dari luar masih bisa masuk ke telinga. Helm ini tidak bisa memberikan perlindungan yang memadai bagi kepala, khususnya bagian muka, dagu, gigi, hidung, leher dan mata. Selain itu, helm ini tidak bisa melindungi pengguna dari hujan, debu, angin, serangga, bahkan kerikil kecil yang beterbangan di jalan karena tidak dilengkapi dengan kaca pelindung pada bagian depannya.

3. Helm 3/4: kelebihan helm jenis ini ialah mampu melindungi bagian kepala, muka, leher, telinga, dan mata, serta berada pada posisi ketiga helm yang cukup aman. Dengan adanya kaca pelindung yang mudah dibuka-tutup, pengguna bisa dengan mudah makan, minum, memotret. Kekurangannya ialah oleh karena didesain semi terbuka maka akan menimbulkan efek dengung di telinga pengguna, dan kurang memberikan perlindungan terhadap muka, dagu, gigi, dan hidung.

4. Helm full face: jenis ini merupakan helm yang paling aman untuk digunakan pengendara motor. Kelebihannya ialah mampu melindungi muka, kepala, leher, telinga, dan dagu dengan sempurna; juga aman dipakai di saat hujan serta melindungi pengguna dari debu, kerikil atau serangga di jalan. Helm jenis ini mampu melindungi pengguna dari cedera yang tidak diinginkan saat terjadi kecelakaan. Kekurangannya ialah karena tertutup rapat, si pengguna sulit untuk mendengar suara di sekelilingnya, dan tidak praktis bila pengguna ingin makan atau minum di tengah jalan. Bagi pengguna kacamata, helm jenis ini sangat tidak nyaman digunakan dan harganya relatif lebih mahal dibanding jenis lain.

5. Helm flip-up: jenis ini hampir sama dengan helm full face. Kelebihannya ialah memiliki bagian depan yang bisa diputar ke atas (flip-up) sehingga memudahkan pengguna untuk makan, minum atau merokok tanpa harus melepas helm. Helm jenis ini mampu memberikan perlindungan yang cukup baik, sama halnya dengan jenis full-face. Kekurangannya ialah karena bagian depannya bisa dibuka-tutup, maka mungkin bagian tersebut dapat terbuka pada saat terjadi kecelakaan sehingga bisa melukai bagian muka dan dagu pengguna. Selain itu, harga helm jenis ini bisanya lebih mahal dibanding helm jenis full-face dan lainnya. 


\begin{tabular}{|c|c|c|c|c|}
\hline \multicolumn{5}{|c|}{ Jenis-jenis helm } \\
\hline Helm cetok & $\begin{array}{c}\text { Helm half } \\
\text { face/open face }\end{array}$ & Helm 3/4 & Helm full face & Helm flip-up \\
\hline & &
\end{tabular}

Gambar 1. Jenis-jenis helm

\section{Manfaat helm secara umum}

\section{Melindungi kepala dari benturan saat kecelakaan}

Bila secara tiba-tiba pengendara motor terpental dari sepeda motor yang sedang melaju kencang, kemungkinan besar kepalanya akan membentur sesuatu saat mendarat entah itu aspal, batu, pagar pembatas, pohon, rumput, dan lain sebagainya. Kepala merupakan bagian tubuh yang terpenting karena keberadaan otak sebagai pusat kendali dan aktifitas seluruh persarafan sehingga terjadinya sedikit benturan pada kepala telah berpotensi mengganggu sistem saraf. Kasus terberat bila bagian dalam kepala mengalami cedera, seperti retaknya tulang kepala yang berpotensi menimbulkan pendarahan otak atau tersumbat dan pecahnya pembuluh darah; kesemuanya ini merupakan faktor dominan penyebab kematian. ${ }^{6}$

Akibat kecelakaan pada organ selain kepala relatif berdampak kecil bagi hilangnya nyawa pengendara. Patah kaki, kulit lecet hingga terkelupas, bahkan terpisahnya kaki dari badan merupakan luka yang relatif tidak mendominasi penyebab kematian. ${ }^{6}$

Penggunaan helm pada pengendara kendaraan roda dua dapat mengurangi dampak benturan kepala. Jenis dan kekuatan terhadap daya tekanan helm menentukan tinggi rendahnya kemampuan melindungi kepala. ${ }^{6}$

Helm dengan komposisi bahan plastik tipis mudah pecah dan tingkat perlindungannya sangat rendah; helm jenis ini tidak cocok sebagai kelengkapan berkendaraan, bahkan keberadaannya sebaiknya dihindari karena ketika terjadi kecelakaan kemungkinan helm akan pecah dan melukai pengguna.

Helm dengan komposisi bahan plastik tebal dan berlogo Standar Nasional Indon-esia (SNI) layak dijadikan pilihan sebagai kelengkapan berkendara karena helm jenis ini telah teruji secara ilmiah melalui berbagai percobaan dengan menggunakan berat tekanan maksimal. ${ }^{6}$

\section{Melindungi mata dari angin, debu, dan kotoran serta benda keras lainnya}

Terdapat banyak ketidaknyamanan yang bisa berujung pada kecelakaan jika berkendara sepeda motor tanpa helm yang mempunyai kaca pelindung, yaitu: mata kelilipan debu dan kotoran sehingga sulit melihat dengan jelas, kepala bisa cedera jika terkena timpukan atau jatuhan benda keras, serta angin yang kencang bisa memicu terjadinya penyakit Bell's palsy. ${ }^{6}$

\section{Melindungi kepala dari panasnya terik matahari}

Kulit bisa terkena kanker kulit yang sangat berbahaya bila sering terpapar oleh teriknya matahari. Selain itu, kulit bisa terbakar oleh sinar matahari sehingga akan terasa tidak nyaman. Juga warna kulit akan berubah menjadi lebih gelap yang akan mengurangi keindahan penampilan. $^{6}$

\section{Melindungi kepala dari basah air hujan}

Untuk sebagian orang, daerah kepala harus tetap kering agar tidak jatuh sakit. Helm akan sangat membantu ketika hujan 
turun secara mendadak pada saat berkendara. Bila menggunakan helm yang tidak standar seperti helm cetok atau helm proyek, maka kemungkinan untuk basah pada bagian kepala sangat besar. ${ }^{6}$

\section{Membuat penampilan menjadi lebih baik (segi estetika)}

Helm bisa menunjukkan serta meningkatkan status sosial seseorang. Individu dengan status ekonomi menengah ke bawah tampak terlihat berasal dari kalangan elit dengan sepeda motor keren serta kelengkapan berkendara yang keren, termasuk helmnya. Tanpa helm yang bagus dan bersih, maka rasa percaya diri seseorang bisa turun. ${ }^{6}$

\section{Mematuhi peraturan lalu lintas dalam menggunakan kendaraan bermotor}

Dengan memakai helm yang sesuai dengan anjuran pemerintah baik untuk pengemudi sepeda motor maupun penumpang yang dibonceng, maka polisi tidak akan menilang untuk masalah helm. Selain menggunakan helm, pengendara juga wajib menaati peraturan berlalulintas yang baik agar aman bagi diri sendiri dan pengguna jalan lainnya.

\section{CEDERA KEPALA}

\section{Definisi cedera kepala}

Cedera kepala adalah cedera yang meliputi trauma kulit kepala, tengkorak, dan otak. Cedera kepala dapat berdampak terjadinya gangguan neurologik yang sangat serius (Gambar 2).

Pada cedera kepala, tulang tengkorak yang tidak terlindung oleh kulit hanya mampu menahan benturan sampai 40 pound/inch ${ }^{2}$, tetapi bila terlindung oleh kulit maka dapat menahan benturan sampai 425.900 pound/inch ${ }^{2}$. Selain gangguan pada kulit kepala dan patah tulang tengkorak, cedera kepala dapat pula mengakibatkan perdarahan dalam rongga tengkorak berupa perdarahan epidural, subdural, dan subaraknoid, kerusakan selaput otak dan jaringan otak. ${ }^{8}$

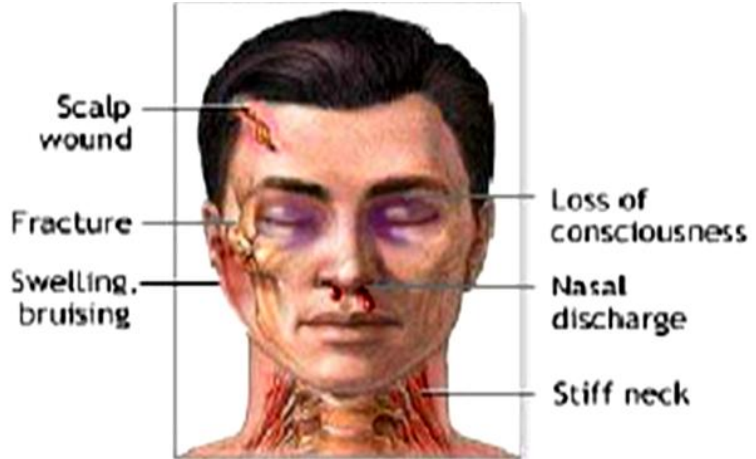

Gambar 2. Gambaran cedera kepala dari anterior.

\section{Etiologi cedera kepala}

Cedera kepala dapat diakibatkan oleh KLL, kecelakaan kerja, trauma saat berolah raga, terjatuh, kejatuhan benda, pukulan pada kepala, dan luka tembak. ${ }^{4,9}$ Umumnya, cedera kepala merupakan akibat dari salah satu atau kombinasi dari dua mekanisme dasar yaitu kontak bentur dan guncangan lanjut. ${ }^{10}$

Cedera kontak bentur terjadi bila kepala membentur atau menabrak sesuatu objek tertentu atau sebaliknya, sedangkan cedera guncangan lanjut yang sering kali dikenal sebagai cedera akselerasideselerasi, merupakan akibat peristiwa guncangan kepala yang hebat, baik yang disebabkan oleh pukulan maupun bukan karena pukulan. ${ }^{10}$

\section{Klasifikasi cedera kepala}

Berat ringannya cedera kepala bukan didasarkan berat ringannya gejala yang muncul setelah cedera kepala. Terdapat beberapa klasifikasi yang dipakai dalam menentukan derajat cedera kepala, yaitu mekanisme terjadinya cedera kepala, beratnya cedera kepala, dan patologi cedera kepala. ${ }^{8}$

\section{Mekanisme cedera kepala}

Berdasarkan mekanisme, cedera kepala dibagi atas cedera kepala tumpul dan cedera kepala tembus. Cedera kepala tumpul biasanya berkaitan dengan kecelakaan mobil atau motor, terjatuh, atau pukulan benda tumpul. Cedera kepala tembus disebabkan oleh peluru 
atau tusukan. Adanya penetrasi selaput durameter menentukan apakah suatu cedera termasuk cedera tembus atau cedera tumpul. $^{8}$

\section{Beratnya cedera kepala}

Glascow coma scale (GCS) digunakan untuk menilai secara kuantitatif kelainan neurologik dan dipakai secara umum dalam deskripsi beratnya cedera kepala. Kategori cedera kepala ringan (CKR) bila GCS 13-15; cedera kepala sedang (CKS) bila GCS 9-12; dan cedera kepala berat $(\mathrm{CKB})$ bila $\mathrm{GCS} \leq 8 .{ }^{8}$

\section{Patologi cedera kepala}

Terdapat dua kategori cedera kepala berdasarkan patologi, yaitu cedera kepala primer dan kerusakan otak sekunder. Cedera kepala primer dapat berupa fraktur linier atau depresi basis kranii, kebocoran likuor, cedera fokal yang berupa kontusi coup atau counter-coup, hematom epidural, subdural, atau intraserebral, cedera difus yang berupa kontusi ringan atau klasik atau berupa cedera aksonal difusa, trauma tembak. ${ }^{11}$

Kerusakan otak sekunder dapat berupa gangguan sistemik akibat hipoksia, hipotensi, gangguan metabolisme energi, dan kegagalan otoregulasi; hematom traumatika epidural, subdural (akut dan kronis), dan intraserebral; edema serebral perifokal generalisata; dan pergeseran otak (brain shift) yang berakibat herniasi batang otak. ${ }^{11}$

\section{Prognosis}

Skor GCS penting untuk menilai tingkat kesadaran dan berat ringannya trauma kapitis. Pemulihan fungsi otak tergantung kepada beratnya cedera yang terjadi, usia, lamanya penurunan kesadaran, dan bagian otak yang terkena. Masalah yang sering timbul selama masa pemulihan ialah hilangnya ingatan akan peristiwa yang terjadi sesaat sebelum terjadinya cedera (amnesia retrograd), perubahan perilaku, ketidakstabilan emosi, gangguan tidur, dan penurunan tingkat kecerdasan. ${ }^{11}$

\section{HUBUNGAN CEDERA KEPALA DENGAN KLL}

KLL tidak lepas dari perkembangan pesat dari perindustrian otomotif akhirakhir ini dan kemampuan daya beli masyarakat untuk kendaraan bermotor. Hal ini menyebabkan peningkatan terjadinya KLL di jalan raya. Da'i Bachtiar menyebutkan bahwa penyebab KLL ialah sebagai berikut: faktor manusia (91\%), faktor kendaraan (5\%), faktor jalan (3\%), dan faktor lingkungan (1\%).

Hasil penelitian yang dilakukan oleh Wilson dan Stimpson dari University of North Texas Health Science Center yang dipublikasikan dalam American journal of public health mengatakan bahwa kenaikan angka penggunaan short message service ( $\mathrm{sms}$ ) yang cepat telah mengakibatkan ribuan kematian akibat KLL. ${ }^{1}$ Faktor-faktor penyebab KLL dari pihak pejalan kaki ialah konsentrasi yang kurang baik, kelelahan fisik dan mental (termasuk keadaan sakit dan mabuk), tidak mematuhi peraturan lalu lintas yang berlaku bagi pengguna jalan, serta kelainan jiwa dan kepribadian. ${ }^{11,12}$

Cedera kepala sudah menjadi masalah utama kesehatan masyarakat di seluruh negara, dan lebih dari dua pertiga dialami oleh negara berkembang. ${ }^{12,13}$ Cedera kepala lebih sering terjadi pada laki-laki usia produktif, karena aktivitas dan mobilitasnya lebih tinggi daripada perempuan. Selain dapat menyebabkan kematian, cedera kepala juga dapat menurunkan produktivitas dan menyebabkan kecacatan permanen. ${ }^{15}$

Cedera kepala akibat trauma sering dijumpai di lapangan. Di Amerika Serikat, $10 \%$ penderita cedera kepala meninggal sebelum tiba di RS dan lebih dari 100.000 penderita menderita berbagai tingkat kecacatan akibat cedera kepala tersebut. Di negara berkembang seperti Indonesia, perkembangan ekonomi dan industri berdampak peningkatan frekuensi cedera kepala. ${ }^{16,17}$ Cedera kepala dapat melibatkan seluruh lapisan, mulai dari lapisan kulit kepala, tulang tengkorak, duramater, vaskular otak sampai jaringan otak itu 
sendiri, baik berupa luka tertutup maupun trauma tembus. ${ }^{13}$

\section{Cara untuk mematuhi peraturan lalu lintas pada kendaraan bermotor}

Dengan memahami dan mematuhi Undang-Undang Lalu Lintas dan Angkutan Jalan Raya (UU No. 22 Tahun 2009) beserta peraturan terkait, maka setiap pengendara kendaraan bermotor wajib membawa Surat Ijin Mengemudi (SIM) dan Surat Tanda Nomor Kendaraan (STNK) yang sah, memakai helm pengaman bagi pengendara dan pembonceng sepeda motor, memasang sabuk pengaman bagi pengemudi kendaraan bermotor roda empat, mematuhi ramburambu lalu lintas, ketentuan tentang batas minimum/maksimum kecepatan mengemudi/mengendarai kendaraan, dan penggunaan lampu utama kendaraan bermotor, serta sopan berlalu lintas. ${ }^{18}$

\section{SIMPULAN}

Meningkatnya jumlah pengguna kendaraan bermotor seiring dengan meningkatnya kejadian KLL. Cedera kepala akibat KLL dapat berakibat yang sangat serius, antara lain kematian. Selain mematuhi aturan lalu lintas, salah satu cara praktis yang dapat mengurangi dampak cedera kepala ialah menggunakan helm saat berkendara.

Benturan saat kecelakaan dapat menyebabkan cedera kepala baik ringan, sedang, maupun berat, yang dapat ditentukan dengan pengukuran derajat kesadaran GCS, dan dengan diagnosis yang cepat dan tepat.

\section{SARAN}

Diharapkan para medis dapat memberikan penyuluhan tentang bahaya benturan pada kepala yang dapat menyebabkan cedera kepada masyarakat.

Pemerintah hendaknya mensosialisasikan penggunaan helm wajib ber-SNI bagi pengendara sepeda motor agar terhindar dari cedera kepala berat, yang dapat berakibat kematian.

\section{UCAPAN TERIMA KASIH}

Ucapan terima kasih ditujukan kepada dr. L. Ratulangi, SpF dan Dr. dr. Erwin G. Kristanto, SH, SpF selaku penguji Skripsi, serta seluruh pihak yang baik secara langsung maupun tidak langsung telah menumbuhkan ide dan gagasan pada penulis.

\section{DAFTAR PUSTAKA}

1. Majalah Kedokteran Indonesia. Pola determinan sosiodemografi cedera kepala di Indonesia [homepage on the Internet]. Nodate [cited 2012 Nov 02]. Available from: http/:Indo digital jounlas.org

2. WHO. Cedera kepala akibat kecelakaan lalu lintas; 2004.

3. Polda Jateng. Latar belakang IRMS [homepage on the Internet]. 2012 [cited 2012 Nov 02]. Available from: $\mathrm{http} /$ :ditlantas jateng.com.

4. Wibowo. Studi komparatif helm full face and open face [homepage on the Internet]. 2011 [cited 2012 Nov 02]. Available from: http://scrib.com/ doc/91471759/studi-komparatifpendalaman-helm-full

5. Dunia Ilmu. Pengertian, etiologi, dan klasifikasi cedera kepala [homepage on the Internet]. Nodate [cited 2012 Nov 02]. Available from: http//ilmugreen.com/2012/06/pengerti an-etiologi-dan-klasifikasi.

6. Safety health and environment. Safety riding [homepage on the Internet] 2012 [cited 2012 Nov 02]. Available from: http/: safety-wordpress.com/ safety-health-and environment.

7. Smeltzer SC, Bare BG. Keperawatan Medikal Bedah (terjemahan). Jakarta: EGC; 2001.

8. Budianto A, Widiatmaka W. Ed. Ilmu Kedokteran Forensik. Jakarta: 1997

9. USU. Patofisiologi cedera kepala [homepage on the Internet]. 2010 [cited 2012 Nov 02]. Available from: http//usu-scrib.com/2010/07/patofisio logi-cedera-kepala

10. Satyanegara. Ilmu Bedah Saraf (Edisi 
IV). Jakarta: PT Gramedia Pustaka; 2010.

11. Redaksi sinar grafika peraturan pelaksanaan undang-undang lalu lintas dan angkutan jalan (Edisi Pertama). Jakarta: Radar Jaya Offset dan Penerbit Sinar Grafika, 1993; p. 9-10,20.

12. Putranto LS. Rekayasa Lalu Lintas imdeks, 2008; p.8-22, 134-139.

13. Smith GS, Barss P. Unintentional injuries in developing countries: epidemiology of neglected problem. Epidemiology Rev.1991:13:228-66.

14. Forjuoh SN, Gyebi-Ofosu E. Injury surveillance: should it be a concern to developing countries?. J Public Health Pol. 1993;14:355-9.

15. Mappiwali. Cedera kepala (trauma kapitis) [homepage on the Internet]. 2009. [cited 2012 Nov 02]. Available from: http/:asramedicafkunhas.com./ 2009/05/cedera-kepala-traumakapitis-html

16. American College of Surgeon. Advanced trauma life support for doctors. American college surgeon, 1997:195227.

17. Listiono LD. Ilmu Bedah Saraf Satyanegara. (Edisi Ketiga). Jakarta: Gramedia Pustaka Utama, 1998; p.147-146.

18. Cara untuk mencegah kecelakaan lalu lintas [homepage on the Internet]. Nodate [cited 2012 Nov 02]. Available from: http/Tamanblogger.Com/cara-untuk-mencegahkecelakaan-lalu-lintas-pada-jalan-raya 